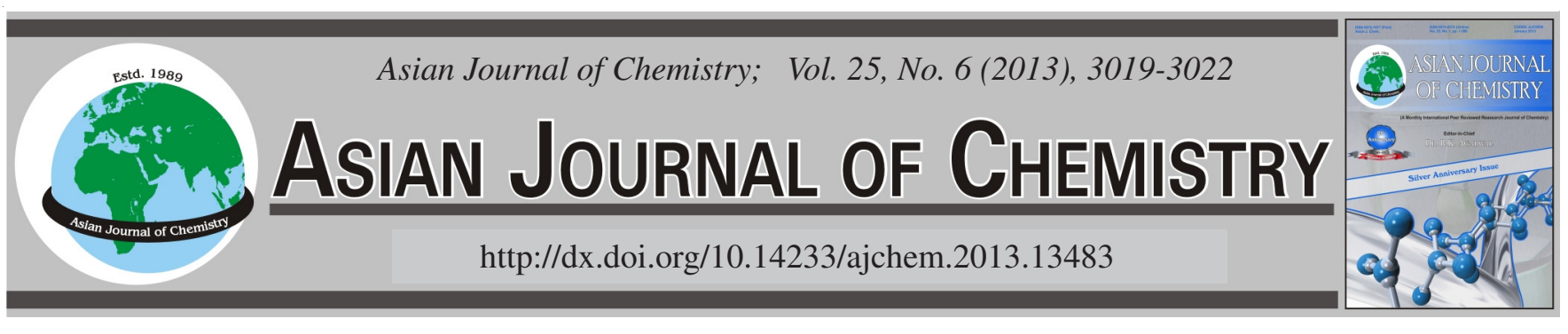

\title{
Reaction of Dimethyl Sulfoxide-Acetic Anhydride with 4-Hydroxy-coumarin and Its Derivatives Under Microwave Conditions
}

\author{
SAIMA QAdiR ${ }^{1, *}$, KHALIQUZ ZAMAN KHAN ${ }^{1}$ and ARIF $\mathbf{J A N}^{2}$
}

${ }^{1}$ Department of Chemistry, University of Kashmir, Hazratbal, Srinagar-190 006, India

${ }^{2}$ Biotechnology Division, Indian Institute of Integrative Medicine, Sanatnagar, Srinagar-190 005, India

*Corresponding author: E-mail: saimaqadir@rediffmail.com

(Received: 20 January 2012;

Accepted: 10 December 2012)

AJC-12510

4-Hydroxycoumarin and various biscoumarins synthesized under microwave conditions were treated with the DMSO-Ac $2 \mathrm{O}$ reagent under the same conditions to yield different products. A comparative account of the reactions with conventional procedure, as reported in literature, has been drawn and improved yields have been obtained in minimum time under microwave conditions for the first time.

Key Words: Biscoumarins, Dimethyl sulfoxide, Acetic anhydride, Microwave irradiation.

\section{INTRODUCTION}

Dimethyl sulfoxide initially used as a dipolar aprotic solvent especially in kinetic studies has found extensive use in synthetic organic chemistry over the years. Kornblum et al. ${ }^{1}$ first used it to bring about the oxidation of allylic halides and alcohols ${ }^{1}$. Subsequent use of sulfoxonium yield as a source of methylene in the preparation of oxiranes and cyclopropanes by Corey and co-workers ${ }^{2,3}$ opened a new area of DMSO chemistry ${ }^{4}$.

Dimethyl sulfoxide has been used as an oxidizing agent as such in combination with electrophillic activators like acetic anhydride, a variety of reactions have been reported ${ }^{4,5}$. 4-Hydroxycoumarin (1a) and derivatives have been reported to react with $\mathrm{DMSO} / \mathrm{Ac}_{2} \mathrm{O}$ under varying conditions of temperature to yield a range of products (Scheme-I) ${ }^{6}$. Prior heating of the reagent has been reported to modify the property of the reagent to yield different products with 4-hydroxycoumarin derivatives. In some cases, either an oxidative rearrangement takes place or the formation of sulfonium yields ${ }^{6}$.

However, the reaction conditions are time consuming and tedious either requiring days at room temperature or hours of reflux at higher temperatures ${ }^{6}$. It was worth doing them under microwave conditions.

\section{EXPERIMENTAL}

Melting points were taken in open capillaries using the electrothermal method on a Labotech/Perfit instrument and are uncorrected. Infrared spectra were recorded on a Perkin Elmer 2000-FT spectrometer. Ultraviolet spectra were measured in chloroform (spectral grade) on a Shimadzu UV1650PC UV/Visible spectrophotometer. ${ }^{1} \mathrm{H}$ NMR spectra were recorded on a $200 \mathrm{MHz}$ instrument using $\mathrm{CDCl}_{3}$ as the solvent and TMS as the internal standard. All the solvents and chemicals used were of AR grade and 4-hydroxycoumarin, in particular, was spectrochemical grade. All the reactions were irradiated in a multimode Sharp Carousel ${ }^{\mathrm{TM}}$ microwave oven at mediumhi power. The products formed have been identified by a comparison of their spectra with those reported in literature wherever possible. Physical properties also agree well in accordance with the data reported in literature ${ }^{6}$.

Dimethyl sulfoxide was dried according to the standard procedure. In all the reactions, a 2:1 v/v ratio of DMSO- $\mathrm{Ac}_{2} \mathrm{O}$

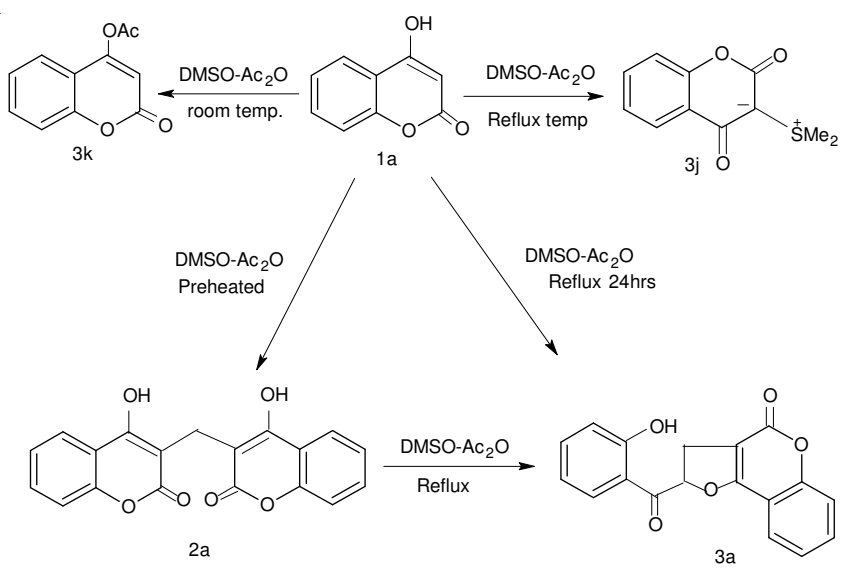

Scheme-I: Reaction of 4-hydroxycoumarin with $\mathrm{DMSO} / \mathrm{Ac}_{2} \mathrm{O}$ to yield different products 
was used. The irradiations were carried out at intervals of one minute irradiation. Reaction mixtures were taken in a $50 \mathrm{~mL}$ Erlenmeyer flasks covered with a cotton plug to avoid moisture. TLC monitoring of the reactions established the completion of reaction or the point of no further progress. The products precipitated out from the reaction mixture were filtered and washed thoroughly with distilled water to remove any DMSO/ $\mathrm{Ac}_{2} \mathrm{O}$, dried and crystallized from appropriate solvent. The mother liquor was extracted with diethyl ether and chromatographed using the appropriate solvent system (chloroform: petroleum ether) $50 / 50(\mathrm{v} / \mathrm{v})$ to afford further amount of the products.

\section{Spectral data of compounds 3a-k}

Spectral data of 2, 3-dihydro-2-(2-hydroxybenzoyl)$\mathbf{4 H}$-furo[3,2c][1]benzopyran-4-one-(3a): ${ }^{1} \mathrm{H}$ NMR (200 $\left.\mathrm{MHz}, \mathrm{CDCl}_{3}\right): \delta 6.35, \mathrm{IH}, \mathrm{q},(\mathrm{O}=\mathrm{C}-\mathrm{CH}-\mathrm{O}-) ; \delta 6.9-7.8,8 \mathrm{H}$, $m,(8 \times \mathrm{ArCH}) ; \delta 3.6,2 \mathrm{H}, \mathrm{m},\left(-\mathrm{CH}-\mathrm{CH}_{2}-\right) ; \delta 11.7,1 \mathrm{H}, \mathrm{s},(\mathrm{OH})$. IR $\left(\mathrm{KBr}, \nu_{\max }, \mathrm{cm}^{-1}\right): 1717.6,1707.2,1649.4 ; \mathrm{MS}(\mathrm{m} / \mathrm{z}): 307.9$ (ESI); m.p. $210-212^{\circ} \mathrm{C}$; $\lambda_{\max }, \mathrm{nm}(\mathrm{MeOH}): 214,255,312,326$.

Spectral data of 7-phenyl-7H-bis-[1]benzopyrano[4,3b: 3',4'-c]pyran-6,8-dione-(3b): ${ }^{1} \mathrm{H} \mathrm{NMR}\left(200 \mathrm{MHz}, \mathrm{CDCl}_{3}\right)$ : $\delta$ 5.2, IH, s, $\left(\mathrm{C}_{6} \mathrm{H}_{5}-\mathrm{CH}\right)$. IR (KBr, $\left.\mathrm{v}_{\max }, \mathrm{cm}^{-1}\right)$ : 1718.1, 1666.3, 1608.8, 1364.9; MS (m/z): 394(ESI); m.p. $320^{\circ} \mathrm{C}$.

Spectral data of 7-(2-chlorophenyl)-7H-bis-[1]benzopyrano[4,3-b:3',4'-c]pyran-6,8-dione-(3c): ${ }^{1} \mathrm{H}$ NMR $(200$ $\left.\mathrm{MHz}_{\mathrm{CDCl}}\right): \delta 5.2, \mathrm{IH}, \mathrm{s},(\mathrm{CH}) ; \delta 7-8,12 \mathrm{H}, m,(12 \times \mathrm{CH})$. IR $\left(\mathrm{KBr}, \mathrm{v}_{\max }, \mathrm{cm}^{-1}\right)$ : 1743.6, 1726.8, 1611.3, 1459.8, 753.7; MS (m/z): 428 (ESI); m.p. $274-277^{\circ} \mathrm{C}$.

Spectral data of 7-(3-chlorophenyl)-7H-bis-[1]benzopyrano[4,3-b:3',4'-c]pyran-6,8-dione-(3d): ${ }^{1} \mathrm{H}$ NMR (200 $\left.\mathrm{MHz}, \mathrm{CDCl}_{3}\right): \delta 5.2, \mathrm{IH}, \mathrm{s},(\mathrm{CH}), \delta 7.1-8.2,12 \mathrm{H}, \mathrm{m},(12 \times$ $\mathrm{CH})$. IR $\left(\mathrm{KBr}, v_{\max }, \mathrm{cm}^{-1}\right)$ : 1727.6, 1651.8, 1629.1, 1610.3, 1602.0, 1367.1, 1111.6, 756.7; MS (m/z): 428 (ESI); m.p. 245$48^{\circ} \mathrm{C}$.

Spectral data of 7-(4-chlorophenyl)-7H-bis-[1]benzopyrano[4,3-b:3',4'-c]pyran-6,8-dione-(3e): ${ }^{1} \mathrm{H}$ NMR (200 $\left.\mathrm{MHz}, \mathrm{CDCl}_{3}\right): \delta 5.2, \mathrm{IH}, \mathrm{s},(\mathrm{CH}), \delta 7.25-8.2,12 \mathrm{H}, \mathrm{m},(12 \times$ $\mathrm{CH})$. IR ( $\left.\mathrm{KBr}, \mathrm{v}_{\max }, \mathrm{cm}^{-1}\right): 1728.8,1714.3,1667.8,1611.7$; MS (m/z): 427.9 (ESI); m.p. $330^{\circ} \mathrm{C}$.

Spectral data of 7-(2-nitrophenyl)-7H-bis-[1]benzopyrano[4,3-b: 3 ',4'-c]pyran-6,8-dione-(3f): ${ }^{1} \mathrm{H}$ NMR (200 $\left.\mathrm{MHz}, \mathrm{CDCl}_{3}\right): \delta 6.1, \mathrm{IH}, \mathrm{s},(\mathrm{CH}), \delta 7.5-8.5,12 \mathrm{H}, \mathrm{m},(12 \times$ $\mathrm{CH})$. IR $\left(\mathrm{KBr}, \mathrm{v}_{\max }, \mathrm{cm}^{-1}\right)$ : $1724.0,1666.1,1610.4,1529.8$, 1364.8; $\mathrm{MS}(\mathrm{m} / \mathrm{z}): 439$ (ESI); m.p. $302^{\circ} \mathrm{C}$.

Spectral data of 7-(3-nitrophenyl)-7H-bis-[1]benzopyrano[4,3-b: 3',4'-c]pyran- 6,8-dione-(3g): ${ }^{1} \mathrm{H}$ NMR (200 $\left.\mathrm{MHz}, \mathrm{CDCl}_{3}\right): \delta 6.3, \mathrm{IH}, \mathrm{s},(\mathrm{CH}), \delta 6.9-8.3,12 \mathrm{H}, \mathrm{m},(12 \times$ $\mathrm{CH})$. IR (KBr, $\left.v_{\max }, \mathrm{cm}^{-1}\right)$ : 1717.4, 1648.6, 1607.9, 1530.8, 1351.4; MS (m/z): 439 (ESI); m.p. $218^{\circ} \mathrm{C}$.

Spectral data of 7-(4-nitrophenyl)-7H-bis-[1]benzopyrano[4,3-b: 3',4'-c]pyran-6, 8-dione-(3h): ${ }^{1} \mathrm{H}$ NMR (200 $\left.\mathrm{MHz}, \mathrm{CDCl}_{3}\right): \delta 5.3, \mathrm{IH}, \mathrm{s},(\mathrm{CH}), \delta 7.3-8.3,12 \mathrm{H}, \mathrm{m},(12 \times$ $\mathrm{CH})$. IR $\left(\mathrm{KBr}, v_{\max }, \mathrm{cm}^{-1}\right): 1720,1650.6,1607.9,1531.8$, 1355.4; $\mathrm{MS}(\mathrm{m} / \mathrm{z})$ : 438.9 (ESI); m.p. $314{ }^{\circ} \mathrm{C}$.

Spectral data of 7-(4-methoxyphenyl)-7H-bis [1]benzopyrano[4,3-b:3',4'-c]pyran-6,8-dione-(3i): ${ }^{1} \mathrm{H}$ NMR (200 MHz, $\left.\mathrm{CDCl}_{3}\right): \delta 7.25, \mathrm{IH}, \mathrm{s},(\mathrm{CH}) ; \delta 7.5-7.7,12 \mathrm{H}$, $\mathrm{m},(12 \times \mathrm{CH}) ; \delta 3.9,3 \mathrm{H}, \mathrm{s},\left(\mathrm{OCH}_{3}\right) . \mathrm{IR}\left(\mathrm{KBr}, v_{\max }, \mathrm{cm}^{-1}\right)$ :
1729.9, 1718.0, 1654.0, 1611.1, 1511.9; MS (m/z): 424 (ESI); m.p. $287-88^{\circ} \mathrm{C}$.

Spectral data of 3-dimethylsulphuranylidenechroman2,4-dione-(3j): ${ }^{1} \mathrm{H}$ NMR (200 MHz, $\left.\mathrm{CDCl}_{3}\right): \delta 3.2,6 \mathrm{H}, \mathrm{s}$; $\mathrm{S}^{+}\left(\mathrm{CH}_{3}\right)$; 7.2-8.1, 4H, (Ar-CH). IR (KBr, $\left.\mathrm{v}_{\max }, \mathrm{cm}^{-1}\right)$ : 1674.8, 1612, 1598.2, 1556.3, 1358.9, 1291.8, 765.8; MS (m/z): 221.8 (ESI); m.p. $190{ }^{\circ} \mathrm{C}$.

Spectral data of 4-acetoxy-1H-benzopyran-2-one(3k): IR (KBr, $\left.v_{\max }, \mathrm{cm}^{-1}\right): 1768.1,1728.3,1608.6,1198.2$, 1175.5, 1138.6; Mp 110-112 ${ }^{\circ} \mathrm{C}$.

\section{RESULTS AND DISCUSSION}

Various dicoumarols synthesized under microwave conditions ${ }^{7}$ were treated with the DMSO- $\mathrm{Ac}_{2} \mathrm{O}$ reagent under the same conditions and improved yields of the products were obtained in contrast to the classical procedure (Schemes IIIV). The advantage of the synthesis is that the reaction time has also considerably shortened from hours to a few minutes (Table-1a,b). The product in all the cases crystallized out of the reaction mixture and the residue on ether-aqueous workup followed by chromatographic purification yielded further of the product. This synthetic conversion of dicoumarols to various derivatives under microwave conditions is much more efficient, time saving and high yielding than the conventional procedure. The mechanism of product formation has been shown in Schemes V-VII. Dimethylsulfoxide being a polar solvent may contradict the increased rate of reaction because of its interaction with the microwaves ${ }^{8-10}$. But the same interaction may have led to a rapid increase in the temperature of reaction mixture on microwave exposure. Additionally, factors like superheating effect $^{8}$, effects according to reaction mechanism ${ }^{9,10}$, may also contribute to increase in reaction rates.

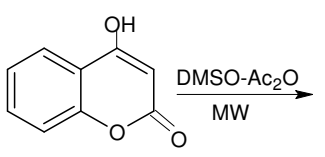

$1 \mathrm{a}$

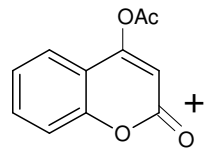

$3 \mathrm{k}$

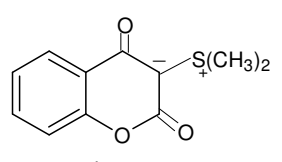

3j
Scheme-II: Microwave-assisted reaction of 4-hydroxycoumarin with dimethyl sulfoxide-acetic anhydride to yield the acetate $(\mathbf{3 k})$ and ylide $(\mathbf{3 j})$ (c)

$2 a$

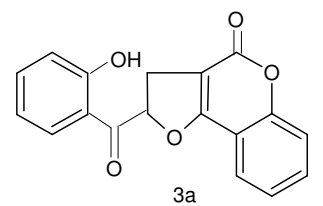

Scheme-III: Microwave-assisted transformation of dicoumarol into dihydrofurocoumarin using dimethyl sulfoxide-acetic anhydride mixture

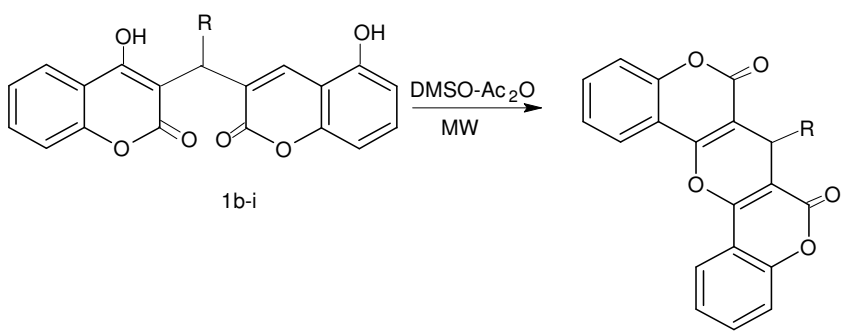

$2 b-i$

Scheme-IV: Microwave-assisted reaction of substituted biscoumarins with dimethyl sulfoxide-acetic anhydride mixture to give products arising out of oxidative rearrangement and cyclisation 


\begin{tabular}{|c|c|c|c|c|c|c|}
\hline \multicolumn{7}{|c|}{$\begin{array}{l}\text { TABLE-1a } \\
\text { SYNTHESIS OF DERIVATIVES FROM VARIOUS DICOUMAROLS AND 4-HYDROXYCOUMARIN } \\
\text { UNDER MICROWAVE IRRADIATION (ERROR } \pm 2)\end{array}$} \\
\hline Dicoumarol (mmol) & $\mathrm{DMSO} / \mathrm{AC}_{2} \mathrm{O} \mathrm{v} / \mathrm{v}$ ratio $(\mathrm{mL})$ & Time $_{\mathrm{MW}}(\mathrm{min})$ & $\mathrm{R}$ & Product & Yield (\%) & Lit. data* \\
\hline $\mathbf{2 a}-6.0$ & $12: 6$ & 4 & $\mathrm{H}$ & $3 \mathbf{a}$ & 66 & $20 \%-10 \mathrm{~h}$ \\
\hline $2 b-7.3$ & $10: 5$ & 2 & $\mathrm{C}_{6} \mathrm{H}_{5}$ & $3 \mathbf{b}$ & 66 & $13 \%-6 \mathrm{~h}$ \\
\hline $2 c-6.7$ & $6: 3$ & 1 & $2 \mathrm{ClC}_{6} \mathrm{H}_{4}$ & $3 c$ & 81 & $61 \%-11 \mathrm{~h}$ \\
\hline $2 d-6.7$ & $4: 2$ & 5 & $3 \mathrm{ClC}_{6} \mathrm{H}_{4}$ & $3 d$ & 65 & $33 \%-8 \mathrm{~h}$ \\
\hline $2 e-6.7$ & $6: 3$ & 1 & $4 \mathrm{ClC}_{6} \mathrm{H}_{4}$ & $3 e$ & 69 & $58 \%-20 \mathrm{mil}$ \\
\hline 2f -4.4 & $10: 5$ & 4 & $2 \mathrm{NO}_{2} \mathrm{C}_{6} \mathrm{H}_{4}$ & $3 f$ & 62 & $10 \%-5.5 \mathrm{~h}$ \\
\hline $2 g-4.4$ & $6: 3$ & 2 & $3 \mathrm{NO}_{2} \mathrm{C}_{6} \mathrm{H}_{4}$ & $3 g$ & 64 & $42 \%-9 \mathrm{~h}$ \\
\hline $2 \mathrm{~h}-2.2$ & $8: 4$ & 6 & $4 \mathrm{NO}_{2} \mathrm{C}_{6} \mathrm{H}_{4}$ & $3 \mathrm{~h}$ & 63 & $26 \%-1 \mathrm{~h}$ \\
\hline $2 \mathbf{i}-6.8$ & $4: 2$ & 3 & $4 \mathrm{CH}_{3} \mathrm{OC}_{6} \mathrm{H}_{4}$ & $3 \mathbf{i}$ & 64 & $28 \%-1.5 \mathrm{~h}$ \\
\hline
\end{tabular}

TABLE-1b

MICROWAVE-ASSISTED REACTION OF 4-HYDROXYCOUMARIN WITH DMSO-Ac ${ }_{2} \mathrm{O}$ MIXTURE (ERROR \pm 2 )

\begin{tabular}{|c|c|c|c|c|c|}
\hline 4-Hydroxycoumarin (mmol) & IMSO/ $\mathrm{Ac}_{2} \mathrm{O}$ mixture $(\mathrm{mL}) 2: 1 \mathrm{v} / \mathrm{v}$ ratio & $\mathrm{Time}_{\mathrm{MW}}(\mathrm{min})$ & Product & Yield $(\%)$ & Lit. data* \\
\hline \multirow{2}{*}{$1 a-6.2$} & \multirow{2}{*}{3} & \multirow{2}{*}{4} & $3 \mathbf{j}$ & 63 & $120^{\circ} \mathrm{C}, 5 \mathrm{~h}, 75 \%$ \\
\hline & & & $3 \mathbf{k}$ & 2 & $110^{\circ} \mathrm{C}, 15 \%, 5 \mathrm{~h}$ \\
\hline
\end{tabular}

In order to achieve the microwave-assisted synthetic conversion, 4-hydroxycoumarin and DMSO- $\mathrm{Ac}_{2} \mathrm{O}$ were subjected to microwave irradiation in the corresponding amounts as shown in Table-1b. 4-Hydroxycoumarin yields a variety of products with the reagent under different temperatures (Scheme-I). At room temperature, its acetate $(\mathbf{3 k})$ is obtained. The same was obtained when performed under microwave irradiation at medium power. But when power level was increased, its ylide (3j) was the major product along with minor amounts of the acetate. The mechanism of the formation of these products has been shown in Scheme-IV. The same products have been obtained when 4-hydoxycoumarin reacts with DMSO- $\mathrm{Ac}_{2} \mathrm{O}$ at $120^{\circ} \mathrm{C}^{6}$.

It is observed that majority of the products have very high melting points as compared with the starting biscoumarins. This may be due to greater magnitude of Vander Waals forces due to high molecular weights. Moreover, decrease in yield in spite of the microwave conditions may be attributed to losses during isolation, chromatography and crystallization.

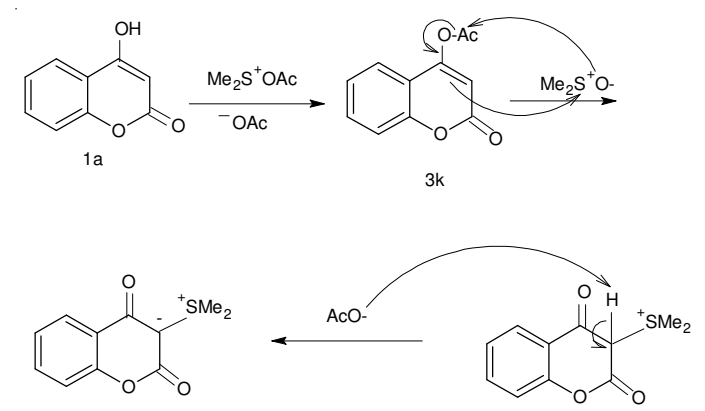

3j

Scheme-V: Mechanism of ylide formation from 4-hydroxycoumarin using dimethyl sulfoxide-acetic anhydride as the reagent

Table-1a shows the relative amounts of the biscoumarins and $\mathrm{DMSO} / \mathrm{Ac}_{2} \mathrm{O}$ mixture taken in each case. The relative amounts of $\mathrm{DMSO} / \mathrm{Ac}_{2} \mathrm{O}$ vary with the biscoumarin taken because of different nature of the reactants as well as to their solubility to some extent in the reagent. The coumarin hydroxyl is converted to oxosulphonium salt $(\mathrm{Y})$ on treatment with $\mathrm{DMSO} / \mathrm{Ac}_{2} \mathrm{O}$. At higher temperature, it cyclizes with the elimination of dimethyl sulfoxide. At room temperature, though, only the spiran $(\mathrm{Z})$ is reported to be formed (Scheme-VIII) ${ }^{6}$. Since the reaction was carried out under microwave conditions, no spiran was formed in this case.

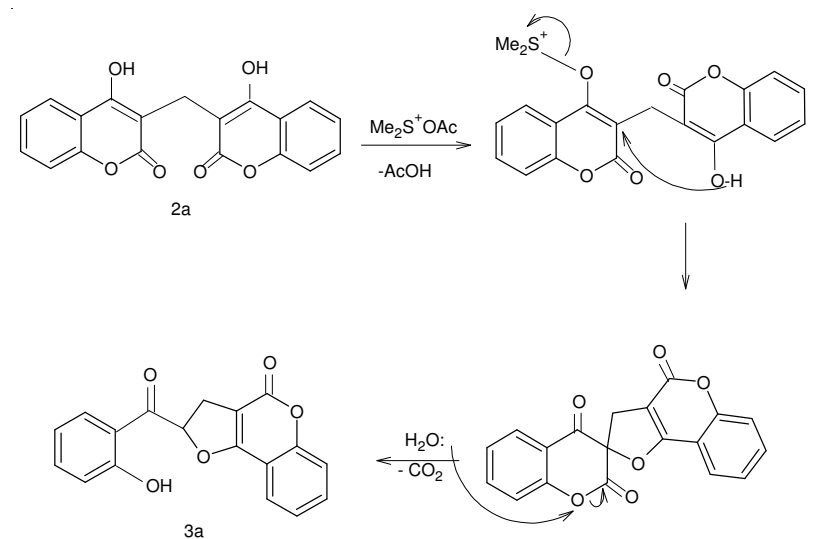

Scheme-VI: Mechanism of dihydrofurocoumarin formation from the reaction of dicoumarol with dimethyl sulfoxide-acetic anhydride

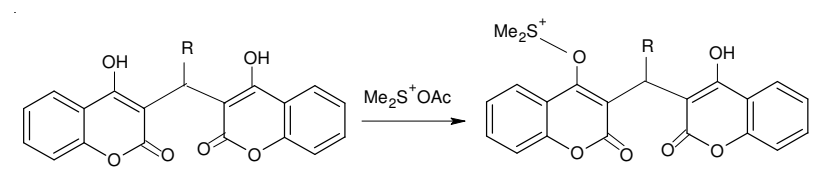

$2 \mathrm{~b}-\mathrm{i}$
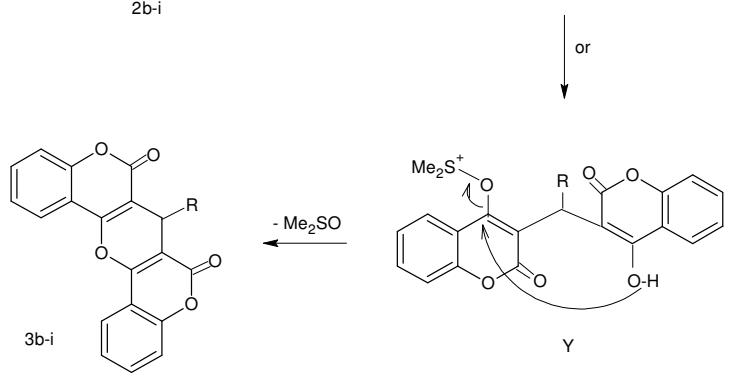

Scheme-VII: Mechanism of the formation of different benzopyranopyrans from the microwave-assisted reaction of dimethylsulfoxide-acetic anhydride mixture with substituted dicoumarols 


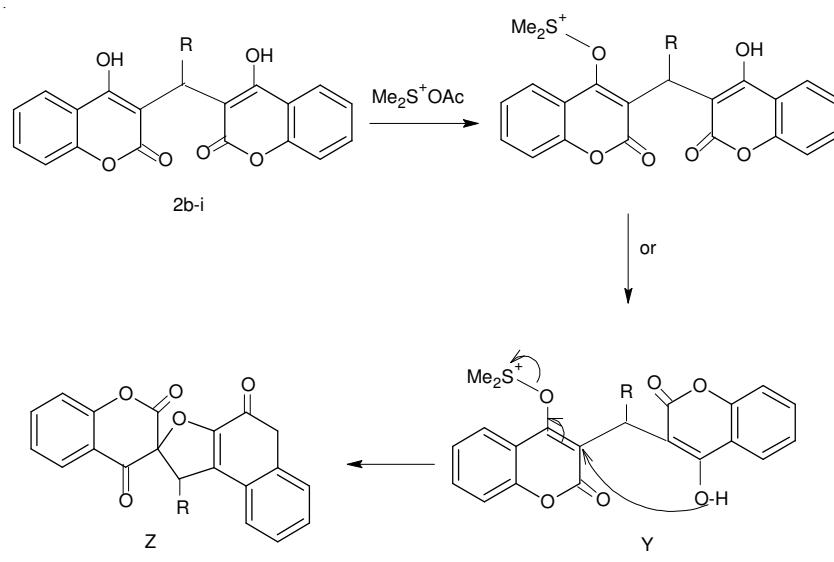

Scheme-VIII: Mechanism of formation of spiran derivative from the reaction of substituted biscoumarin with dimethyl sulfoxide at room temperature

\section{Conclusion}

Dimethyl sulfoxide activated by acetic anhydride reacts with 4-hydroxycoumarin and various biscoumarins under microwave conditions to yield a variety of products. The synthesis is achieved in minimum time and the products obtained have tremendous pharmacological potential.

\section{ACKNOWLEDGEMENTS}

The authors are grateful to the Head, Department of Chemistry, University of Kashmir, Srinagar, for providing the necessary facilities.

\section{REFERENCES}

1. N. Kornblum, W.J. Jones and G.J. Anderson, J. Am. Chem. Soc., 81, 4113 (1959).

2. E.J. Corey and C.U. Kim, Tetrahedron Lett., 14, 919 (1973).

3. E.J. Corey and M. Chaykovsky, J. Am. Chem. Soc., 84, 866 (1962).

4. Technical Bulletin-Reaction Solvent Dimethyl Sulfoxide (DMSO), Gaylord Chemical Corporation P.O. Box 1209 Slidell, LA 70459-1209 (985) 649-5464, 1-110 and references cited therein.

5. Y. Hayashi and R. Oda, J. Org. Chem., 32, 457 (1967).

6. a) K.Z. Khan, N. Minhaj, K. Tasneem, A. Zaman, D. Shiengthong, F.M. Dean and M. Varma, J. Chem. Soc., Perkin Trans. I, 841 (1983); b) G. Appendino, S. Tagliapietra, G.M. Nano and G. Palmisano, J. Chem. Soc., Perkin Trans. I, 2305 (1989).

7. S. Qadir, A.A. Dar and K.Z. Khan, Synth. Commun., 38, 3490 (2008).

8. D.R. Baghurst and D.M.P. Mingos, J. Chem. Soc., Chem. Commun., 674 (1992).

9. A. Hoz, A.D. Ortiz and A. Moreno, Chem. Soc. Rev., 34, 164 (2005).

10. N. Kuhnert, Angew. Chem. Int. Ed., 41, 1863 (2002). 